\title{
Evaluation of Mass Drug Administration through Transmission Assessment Survey in Udupi District of Karnataka, India
}

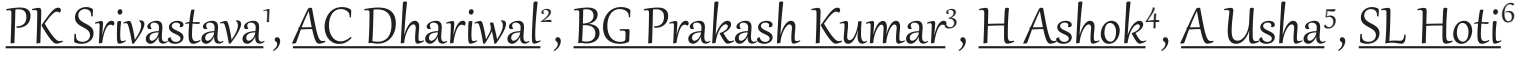 \\ 1,2Directorate National Vector Borne Disease Control Programme, 22-Sham Nath Marg, Delhi, India. \\ ${ }^{3,4}$ Department of Health \& Family Welfare Services, Karnataka, India. \\ ${ }^{5}$ District Surveillance Unit, Tumkur, Department of Health \& Family Welfare Services, Karnataka, India. \\ ${ }^{6} \mathrm{ICMR}$, Belgaum, Karnataka, India. \\ DOI: https://doi.org/10.24321/0019.5138.201933
}

I $\quad \mathbf{N} \quad \mathbf{F} \quad \mathbf{O}$

Corresponding Author:

PK Srivastava, Directorate National Vector Borne

Disease Control Programme, 22-Sham Nath

Marg, Delhi, India.

E-mail Id:

pkmalaria@yahoo.co.in

Orcid Id:

https://orcid.org/0000-0002-7696-3845

How to cite this article:

Srivastava PK, Dhariwal AC, Kumar BGP, Ashok $\mathrm{H}$, Usha A, Hoti SL. Evaluation of Mass Drug Administration through Transmission Assessment Survey in Udupi District of Karnataka, India. J Commun Dis 2019; 51(4): 21-28.

Date of Submission: 2019-11-15

Date of Acceptance: 2019-12-26
$\begin{array}{llllllll}\mathbf{A} & \mathbf{B} & \mathbf{S} & \mathbf{T} & \mathbf{R} & \mathbf{A} & \mathbf{C} & \mathbf{T}\end{array}$

Annual Mass Drug Administration (MDA) of single dose of antifilarial drugs to all the eligible population was initiated in 2004 in Udupi district, a known endemic district for bancroftian filariasis. Nine rounds were implemented in this Implementation Unit (IU) with drug coverage ranging from $83 \%$ to $90 \%$ in different MDA rounds and with drug compliance rate of more than $65 \%$ in each of the MDA round. The baseline $\mathrm{mf}$ prevalence of $1.3 \%$ in 2004 was brought down to $0.09 \%$ in the year 2013. The impact assessment performed after 9 MDA rounds revealed $<1 \% \mathrm{mf}$ prevalence in each of the sentinel and spot check sites. The $\mathrm{mf}$ prevalence was further measured in 10 additional sites, which recorded $<1 \% \mathrm{mf}$ prevalence in all the sites. Having qualified for Transmission Assessment Survey (TAS), school-based survey was conducted in March 2014 in EUvaluation unit (EU) targeting 6 to 7-year children. The number of clusters, sample size, sampling fraction, critical cut off value, clusters and additional clusters to be sampled were estimated using Survey Sample Builder tool. A total of 1579 children from 53 clusters were screened against the target of 1553 and 5 were found positive for filaria antigen $(0.3 \%)$ against the critical cut off value of 18 and hence the decision of stoppage of further rounds of MDA was taken. The "Post MDA Surveillance" was implemented in the EU, wherein the mf prevalence among 5-9-year age group in sentinel and spot check sites was measured annually for two years. The $\mathrm{mf}$ prevalence of such surveys was less than 1\%. The second TAS conducted in 2016 after a gap of 2.4 years has shown presence of $0.6 \%$ filarial antigenemia thus passing the second TAS also.

Keywords: MDA, Evaluation Unit, FTS, ICT, TAS 


\section{Introduction}

The annual Mass Drug Administration (MDA) of antifilarial drugs to all the eligible population living in filaria endemic areas was launched in India in 2004 to achieve the goal of Elimination of Lymphatic Filariasis (ELF) by 2015 as set under National Health Policy framed in 2002. ${ }^{1}$ The goal was in agreement with the Global Programme to Eliminate Lymphatic Filariasis (GPELF). ${ }^{2}$

Udupi one of the coastal districts of Karnataka state was classified as bancroftian filariasis endemic region based on the historical Microfilaria (mf) surveys as well on the presence of lymphoedema cases and thus included for MDA. The MDA in this Implementation Unit (IU) was introduced in 2004 with DEC alone and 9 rounds were implemented since then till 2012.

Supervised drug administration to all the eligible population in the IU was carried out through trained Drug Administrators while keeping the community open to the programme. Such an effort yielded the drug coverage ranging from $83 \%$ to $90 \%$ in different rounds of MDA. Albendazole was co-administered with DEC since 2008.

The IU has reported 723 filariasis manifestation cases with 628 lymphoedema and 95 hydrocele cases. Morbidity management practices were demonstrated to the patients through the existing health care facilities in both routine and campaign mode activity. Surgical operations were performed to 450 eligible hydrocele cases.

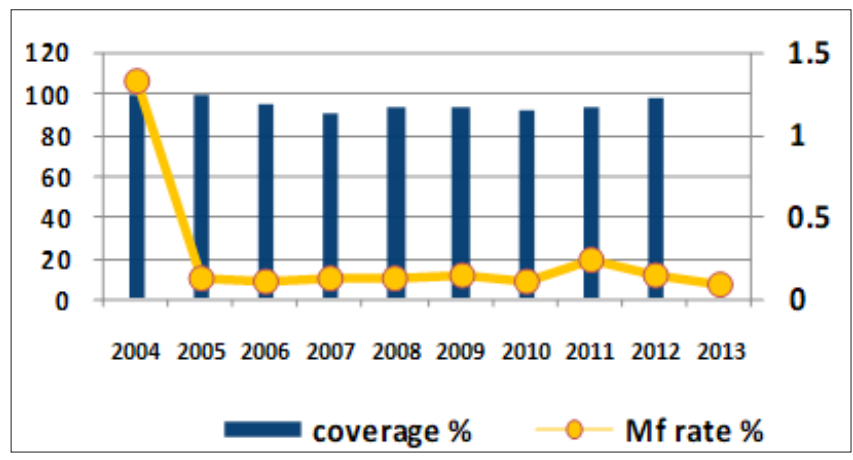

Figure I.Microfilaria prevalence and drug coverage
The mf survey was conducted in 4 sentinel sites and 4 spot check sites before each MDA round. Spot check sites were changed each time while keeping the sentinel sites as fixed units. A total of 44 representative sites i.e. 4 sentinel and 40 spot check sites were thus surveyed since 2004 as an assessment tool. The base line $\mathrm{Mf}$ rate which was $1.3 \%$ was reduced to $0.09 \%$ in 2013 in response to good drug coverage (Figure 1).

The IU has implemented more than 5 MDA rounds; has shown drug coverage of more than $65 \%$ in all the rounds; and the $\mathrm{mf}$ survey carried out before the $9^{\text {th }}$ round, which was the last round has revealed the $\mathrm{mf}$ prevalence in each of the sentinel and spot check site to be less than $1 \%$. The IU has thus full filled WHO criteria for taking up Transmission Assessment Survey (TAS). ${ }^{3}$ TAS, a WHO protocol to help in determining whether the region has reached critical threshold of infection, for making decision to stop or to continue MDA. TAS was implemented in the IU and number of positives reported during the survey was below the critical threshold and hence MDA was stopped. The process of TAS is described in this article.

\section{Materials and Methods}

\section{Eligibility Criteria}

The IU was verified for its eligibility for taking up TAS and following observations were made:

1. It has completed more than 5 rounds of MDA.

2. It has achieved epidemiological drug coverage of more than $65 \%$ in each of the round.

3. It has reported less than $1 \% \mathrm{mf}$ prevalence in each of the sentinel and spot check site in the mf survey conducted before last round of MDA.

In view of the fulfillment of all the criteria by the IU as per WHO TAS guidelines 2011, it was decided to conduct TAS. However, before proceeding to TAS it was preferred to ensure the lower $\mathrm{mf}$ prevalence further, and $\mathrm{mf}$ survey was thus carried out in 10 additional sites as per Draft National Guidelines for Transmission Assessment Survey 2013-14. The $\mathrm{mf}$ prevalence in all the sites surveyed was individually less than $1 \%$ with 7 sites reporting zero prevalence (Table 1 ).

Table I.The mf prevalence and drug coverage showing eligibility of IU for TAS

\begin{tabular}{|c|c|c|c|c|c|c|c|c|c|c|c|}
\hline $\begin{array}{c}\text { Year of } \\
\text { initiation of } \\
\text { MDA in EU }\end{array}$ & $\begin{array}{c}\text { Date } \\
\text { of last } \\
\text { MDA }\end{array}$ & $\begin{array}{l}\text { Indicator } \\
\text { year }\end{array}$ & 2004 & 2005 & 2006 & 2007 & 2008 & 2009 & 2010 & 2011 & 2012 \\
\hline \multirow{4}{*}{2004} & \multirow{4}{*}{$\begin{array}{c}\text { March } \\
2013\end{array}$} & $\begin{array}{c}\text { MDA } \\
\text { coverage }\end{array}$ & 90 & 90 & 90 & 86 & 86 & 85 & 83 & 86 & 88 \\
\hline & & BSE & 4443 & 4217 & 4508 & 4172 & 4281 & 4119 & 4207 & 4141 & 4401 \\
\hline & & $\mathrm{Mf}+\mathrm{ves}$ & 58 & 5 & 5 & 5 & 5 & 6 & 4 & 10 & 6 \\
\hline & & Mf rate (\%) & 1.31 & 0.12 & 0.11 & 0.12 & 0.12 & 0.15 & 0.10 & 0.24 & 0.14 \\
\hline
\end{tabular}


Individual site wise details of Mf survey in sentinel, spot check and additional sites conducted before TAS

\begin{tabular}{|c|c|c|c|c|c|c|c|c|c|c|c|c|c|c|c|c|c|c|}
\hline Indicators & 푸 & $\tilde{\varkappa}$ & $\stackrel{m}{\simeq}$ & $\underset{\simeq}{\Psi}$ & பี & ヘ & $n$ & シ & 뭉 & 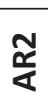 & $\underset{\substack{\mathscr{\alpha} \\
\stackrel{\alpha}{\alpha}}}{ }$ & 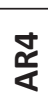 & $\stackrel{\text { 亗 }}{\stackrel{\alpha}{<}}$ & $\begin{array}{l}0 \\
\stackrel{\alpha}{<}\end{array}$ & 余 & $\underset{\substack{\infty \\
\mathbb{\alpha}}}{\infty}$ & 㔽 & 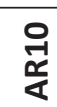 \\
\hline BSE & นٌ & $\underset{n}{n}$ & 옴 & ஸี & ৪ & ஜூ & ભ્તે & $\stackrel{m}{m}$ & $\underset{\text { N }}{\stackrel{\nabla}{ }}$ & 옹 & 옷 & $\begin{array}{l}\stackrel{n}{n} \\
\stackrel{n}{n}\end{array}$ & ○ & $\stackrel{n}{\stackrel{n}{n}}$ & ১ঠ & $\begin{array}{l}\infty \\
\infty \\
\end{array}$ & రิ & 욹 \\
\hline No. Mf+ve & -1 & 0 & -1 & $\sim$ & -1 & 0 & 0 & -1 & -1 & 0 & 0 & 0 & 0 & $N$ & 0 & 0 & 0 & $r$ \\
\hline Mf rate $\%$ & $\stackrel{\infty}{\stackrel{\infty}{+}}$ & $\begin{array}{l}\circ \\
\text { ○ }\end{array}$ & 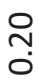 & $\begin{array}{l}0 \\
m \\
0\end{array}$ & 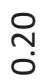 & $\begin{array}{l}\text { ○ } \\
\text { O }\end{array}$ & ○ & $\stackrel{\text { ने }}{\circ}$ & 궁 & $\begin{array}{l}\circ \\
\circ\end{array}$ & $\begin{array}{l}\text { ○ } \\
\text { O }\end{array}$ & ○ & $\begin{array}{l}\text { ○ } \\
\text { ' }\end{array}$ & $\begin{array}{l}\text { nે } \\
\text { n̊ }\end{array}$ & $\begin{array}{l}\text { ○ } \\
\text {. }\end{array}$ & ○ & $\begin{array}{l}\text { ○ } \\
\text { ' }\end{array}$ & $\stackrel{n}{\sim}$ \\
\hline
\end{tabular}

BSE - Number of blood slides examined, R - Random (spot check) site, S - Sentinel site, AR - Additional random site.

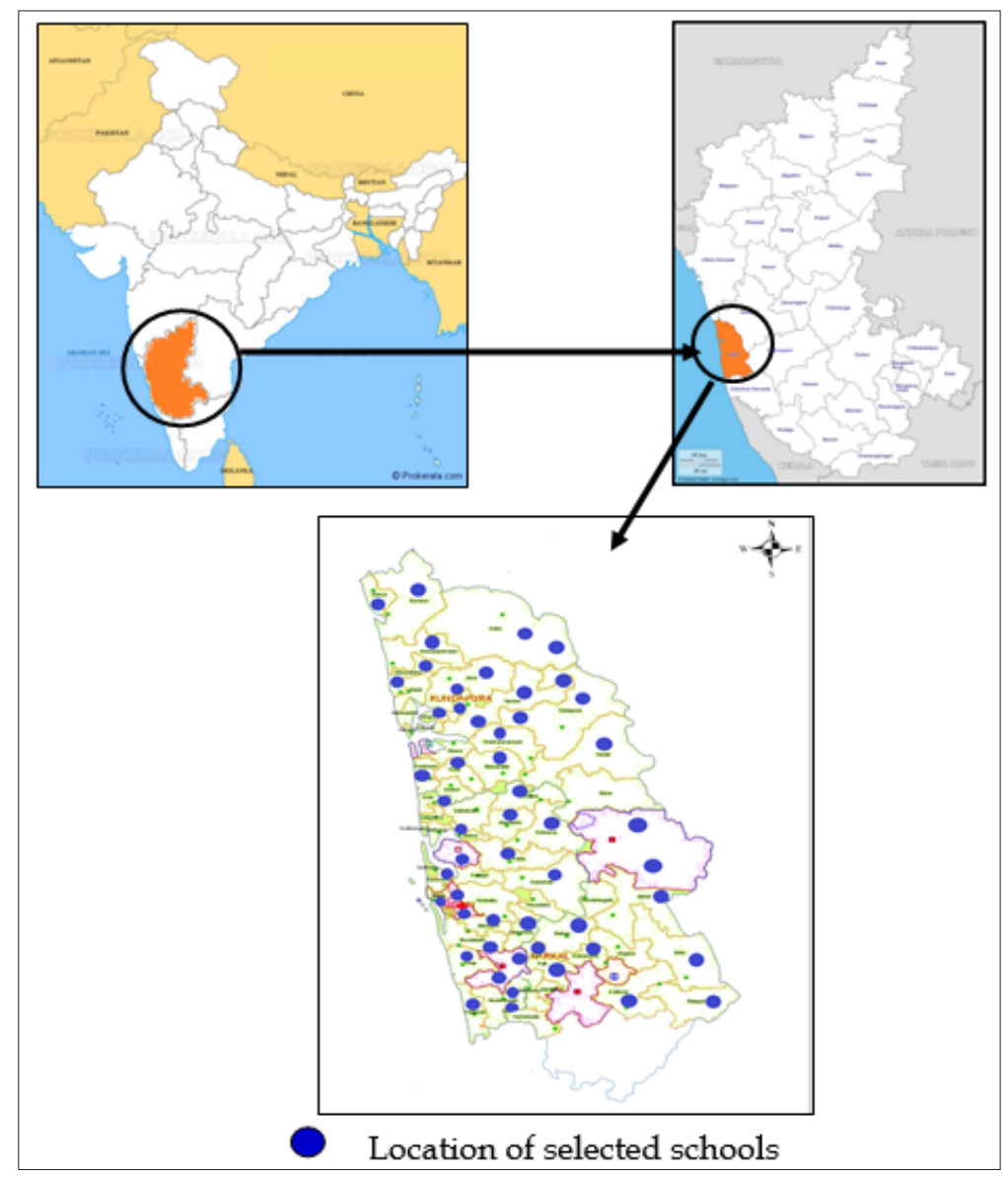

Figure 2.Study site: Schools of Udupi district, Karnataka

\section{Study Area}

The IU i.e. Udupi district has 3 taluks (subdistricts) stretched in $3880 \mathrm{~km}^{2}$ with 1.17 million population. The parasite reported is Wuchereria bancrofti and the vector is $C X$. quinquefasciatus. Considering the size of the population, geographical area and epidemiological features within the IU, the entire IU is taken as one Evaluation Unit (EU) for implementation of TAS.

Table 2.Drug coverage and $\mathrm{mf}$ prevalence in sub IUs

\begin{tabular}{|c|c|c|c|c|c|c|c|c|c|c|c|c|c|c|c|c|c|c|}
\hline \multirow{2}{*}{$\begin{array}{l}\text { Sub } \\
\text { IUs }\end{array}$} & \multicolumn{2}{|c|}{2004} & \multicolumn{2}{|c|}{2005} & \multicolumn{2}{|c|}{2006} & \multicolumn{2}{|c|}{2007} & \multicolumn{2}{|c|}{2008} & \multicolumn{2}{|c|}{2009} & \multicolumn{2}{|c|}{2010} & \multicolumn{2}{|c|}{2011} & \multicolumn{2}{|c|}{2012} \\
\hline & 1 & 2 & 1 & 2 & 1 & 2 & 1 & 2 & 1 & 2 & 1 & 2 & 1 & 2 & 1 & 2 & 1 & 2 \\
\hline Udupi & 95 & & & & 92 & & 86 & & 86 & & 86 & & 01 & & 84 & & 37 & .09 \\
\hline & 91 & 2.98 & 95 & 0.31 & 91 & 0.17 & 89 & 0.06 & 88 & 0.06 & 85 & 0.32 & 85 & 0.24 & 88 & 0.06 & 90 & 0.25 \\
\hline Karkal & 92 & 0.00 & 89 & 0.00 & 81 & 0.00 & 81 & 0.00 & 83 & 0.20 & 82 & 0.10 & 84 & 0.00 & 86 & & 88 & 0.00 \\
\hline
\end{tabular}

1 - Drug coverage (\%), 2 - Mf prevalence (\%). 
All 3 sub IUs have shown the epidemiological drug coverage of more than 65\%; almost similar mf prevalence after initial round of MDA ranging from 0.0 to $0.3 \%$; have similar parasite and similar vector (Table 2 ) justifying consideration of the survey area as one EU.

\section{Study Design}

The WHO protocol was used for implementation of TAS. ${ }^{3}$ The target group selected for knowing the impact of MDA and/or the prevalence of LF infection was 6-7-year children. The rationale for such selection is that, young children born after initiation of MDA should have been protected from infection if the MDAs were effective. Presence of infection in this group is an indicator of recent transmission and unproductive MDAs. The survey would be more feasible if large number of 6-7-year children is available at one place for screening and such possibility could be expected in schools. Numbers of schools functioning in the EU were thus enumerated and numbers of students enrolled in $1^{\text {st }}$ and $2^{\text {nd }}$ standard in those schools were also enumerated. The age limit for enrolment to $1^{\text {st }}$ standard being usually
6 years in India, students of $1^{\text {st }}$ and $2^{\text {nd }}$ standard were considered for the survey under inclusion criteria and others were excluded.

\section{Survey Site}

The population enumerated at 2011 census was used as basis for all further calculations. A total of 30, 272 children in the 6-7-year age group were estimated to be present in the EU during the year of TAS and was calculated taking EUs annual growth rate of $0.59 \%$ into account. The school enumeration has yielded 30,937 students in $1^{\text {st }}$ and $2^{\text {nd }}$ standard. Probability of getting 6-7-year children in schools in this occasion was more than $75 \%$ and thus opted for school-based survey i.e. school is considered as survey site. The EU being the educational hub and migratory core, the out numbering of students to estimated population of 6-7 year is acceptable.

\section{Sampling Strategy}

A total of 937 schools were functioning in the EU with 30,937 students of 6-7 year and hence cluster sampling technique was adopted for sampling.

Table 3.Survey sample builder output

\begin{tabular}{|c|c|c|}
\hline Country: & \multicolumn{2}{|l|}{ India } \\
\hline Name of EU: & \multicolumn{2}{|l|}{ Udupi } \\
\hline \multirow[t]{16}{*}{ Primary Vector: } & \multicolumn{2}{|l|}{ Anopheles or Culex } \\
\hline & \multicolumn{2}{|l|}{ Demographic data on EU (provided by user) } \\
\hline & Population of students in target grade(s): & 30,937 \\
\hline & Total number of schools: & 937 \\
\hline & $\begin{array}{l}\text { Avg. number of students in target grade (s) per } \\
\text { school: }\end{array}$ & 33 \\
\hline & \multicolumn{2}{|c|}{$\begin{array}{l}\text { *Note, if any of the above information is incorrect, click on the 'Back to "Start Here"' button } \\
\text { and then click 'edit EU information' }\end{array}$} \\
\hline & \multicolumn{2}{|c|}{$\begin{array}{l}\text { Cluster Survey of School Entrants } \\
\text { Survey Sampling Methodology (calculated by program) }\end{array}$} \\
\hline & Sample size for cluster design & 1,556 \\
\hline & Number of Clusters ${ }^{1}$ & 53 \\
\hline & Sampling Fraction (of children within the schools) 1 & Test all children in the target grade(s) \\
\hline & Sampling Interval (of children within the schools) ${ }^{1}$ & N/A \\
\hline & $\begin{array}{l}\text { Critical Cut-off (maximum \# positive ICT/Brugia } \\
\text { Rapid results allowable for country to "Pass") }\end{array}$ & 18 \\
\hline & \multicolumn{2}{|l|}{ Based on a $10 \%$ absentee rate } \\
\hline & 1. Select schools to sample & 2. Generate Lists A \& B \\
\hline & \multicolumn{2}{|c|}{$\begin{array}{l}\text { Lists corresponding to the children selected for sampling out of all students in target } \\
\text { grade(s), per school }\end{array}$} \\
\hline & List A & List B \\
\hline
\end{tabular}


The Survey Sample Builder (SSB) was used to automate the calculation for determining the sample size, cluster size, sampling fraction, sampling interval, critical cutoff, clusters and additional cluster (optional) to be visited. Inputs like, parasite type, vector spp., number of schools, number of students in $1^{\text {st }}$ and $2^{\text {nd }}$ standard, absentee rate - which was considered as $10 \%$ in this instance - and number of additional schools required were keyed in the SSB tool. As per the SSB output (Table 3) sampling size was 1556, cluster size was 53 . There was no sampling fraction as the average number of students per school in the EU was 33 and sampling interval was nil in absence of sampling fraction. The critical cut off was 18. Ten additional schools were opted to achieve the target sampling size in speculation of excess absenteeism.

\section{Survey Implementation}

After completion of pre TAS activities, an intersectoral coordination meeting involving the department of Education was convened. Further, a written communication from the highest district administrative authority was also issued to all the selected schools well in advance informing and seeking their cooperation for the survey. List of Primary Health Centers (PHCs) to which the selected schools belong were prepared and qualified health personnel from these PHCs were identified and were trained for TAS. Ten teams each consisting 5 members were formed. Each team was assigned with set number of schools and children for screening in a fixed interval of time. Presence of a Medical Officer during the screening period was made mandate not only for management of any untoward incidents during the survey but also for supervision of the survey.

The survey was taken up during $3^{\text {rd }}$ week of March 2014. The Immuno Chromatographic Test (ICT) cards supplied by the WHO were used for screening the students. The ICT is sensitive for detecting $W$. bancrofti antigen. The standard protocol was followed with respect to storage, transportation and card preparation of ICT. Each day the team visited the school assigned to it, consulted the school authority and proceeded with the screening of students. All the members of the team had fixed duty to perform, identification and registration of the student with the aid of class teacher was done by the first person then the student was directed to the Card preparer who entered student identity number on the test card after ensuring the student's identity and passed the test card to the Sample collector. The sample collector, while following all the safety measures to be followed for collection of human sample, collected the $100 \mu \mathrm{l}$ of blood from the subject in the capillary tube provided with the test kit, the sample was then transferred to the sample pad in the test kit and the kit was forwarded the Card reader who noted the end time of blood transfer as well the reading time on the card. The test cards were then read exactly at 10 minutes from the sample transfer and the result of each card was entered into the register and the same was marked on the test card also. All positive test cards were confirmed by the Medical officer present with the team. The procedure was repeated for all the students. The last person has assisted the other team members and comforted the students.

\section{Result Interpretation}

The test cards (ICT) have ' $C$ ' and ' $T$ ' markings representing control and test areas respectively. A clear pink line on ' $C$ ' and/or ' $\mathrm{T}$ ' area is indicative of result reading. The cards with only control line were considered negative. Cards showing both control and test lines were classified as positive. These positives cards were further graded as strong and weak positives based on the colour intensity of the test line. If the test line was as strong as control line it was considered as strong positive and on the other hand if the test line colour was faint it was treated as weak positive. The cards with no lines are treated as invalid and the cards with only test line are also deemed as invalid. The cards were read under adequate lighting. Infection prevention practices and measures for safe disposal of the bio waste were adhered strictly.

\section{Result}

Out of 937 schools in the EU 53 schools were visited for screening of students. A total of 1950 students were enrolled in these 53 schools and 1579 children were screened with ICT against the sample size of 1556. Out of these 1579 tests, 1574 were negative and 5 tests were positive with one weak positive thus showing the Ag prevalence of $0.3 \%$. None of the tests were invalid. All the positive cases were treated with full course of 12-day treatment. Epidemiological investigation of positive cases has revealed that 2 cases are imported which migrated from other endemic areas of the state. The 5 positive cases are from different areas of the EU. Microfilaria survey was carried out in houses around each positive case and a total of 546 blood smears were collected and none were positive for microfilaria. The same was true for antigen positive children also. The ICT survey in the current EU had yielded 5 positives against the critical off of 18 .

\section{Post MDA Surveillance}

After the stoppage of MDA, infection prevalence was measured among children of 5-9-year age group in 4 sentinel and 4 spot check sites. The sentinel sites which were selected during MDAs were retained for post MDA surveillance also. A minimum of 50 smears were collected from each site during 2014 after 6 months of TAS and the process was repeated in 2015 also. The blood films were examined by qualified Laboratory Technicians and found that none of them are positive for microfilaria, indicating the LF transmission in the areas of survey to be zero. 


\section{Transmission Assessment Survey, Round 2}

Second round of TAS was implemented in the EU after a gap of 2 years and 4 months from the first round. The survey was taken up during last week of July 2016. The same protocols explained above for TAS 1 were followed, however, during this round Filariasis Test Strips (FTS) were used instead of ICTs. A total of 1671 FTSs were used out of which 33 were invalids and it was ensured that invalid tests are repeated with other students. Thus 1638 valid tests were conducted on students in 56 schools against the sample size of 1556 . The survey has yielded $10 \mathrm{Ag}$ positives against the critical cut off of ' 18 '. The EU has thus passed the second TAS also. One positive student is from a neighboring endemic district who travels daily to the school in the EU. Other 9 cases belong to 6 different sites in the EU. Three sites have reported 2 cases each while other 3 sites have reported 1 case each.

\section{Discussion}

Lymphatic filariasis or elephantiasis, a disabling mosquito borne parasitic disease is endemic in 73 countries. ${ }^{4}$ It is one of the six diseases that can potentially be eradicated ${ }^{5}$ and is the fourth most common cause of disability worldwide. ${ }^{6}$ Considering the availability of advance tools, success of control programmes and the biological factors favoring elimination of this infection, the World Health Assembly has passed the resolution for elimination of LF and hence the GPELF was launched by the WHO in 2000 with the goal of eliminating LF as a public health problem by the year 2020. The strategies adopted to achieve the goal are interruption of transmission by administering combinations of antifilarial drugs to entire populations at risk which prevents new infection and to alleviate suffering and disability by morbidity management and hydrocelectomy. ${ }^{7}$ India being the signatory to WHA, launched MDA for ELF in 2004 covering 600 million at risk population in 250 endemic districts. $^{8}$

Planning, implementation, and decision-making guidelines were provided when the programme was launched however, the threshold levels given were highly conservative in the initial guidelines. ${ }^{9,10}$ This issue was resolved in the current Transmission Assessment Survey guidelines as per the inputs from the programmes and researchers. ${ }^{11-13}$

Udupi in Karnataka state is one of such LF endemic districts implemented 9 rounds of MDA since 2004 with drug coverage ranging from $83-90 \%$. At least $65 \%$ treatment coverage for a minimum of 5 annual MDA rounds are required to bring down the $\mathrm{Mf}$ prevalence to below critical threshold. ${ }^{14}$ The independent assessment of drug coverage in the EU has reported drug compliance varying from $66 \%$ to $80 \%{ }^{15}$ in different years this has resulted in reduction of mf prevalence below $1 \%$ in sentinel and spot check sites.
However, due to the varying coverage, the reduction of infection prevalence took more than 5 rounds of MDA. Independent assessment of drug coverage through medical colleges was carried out as the gap between drug coverage and compliance was noticed in earlier studies in other parts of India. ${ }^{16-19}$ Studies have shown that number of MDAs required in bringing down the infection prevalence is proportional to baseline prevalence of infection, intensity of transmission, parasite spp., vector spp. and their density. ${ }^{20-26}$

The impact indicator for MDA in the current study is Mf prevalence which is measured before each round of MDA in selected sentinel and spot check sites. Achieving the desired level of microfilaremia in all the sentinel, spot check sites and also in 10 additional sites, a standardized TAS is performed in the IU to confirm that interventions have reduced the infection levels below a critical threshold. ${ }^{7}$ The ICT/ FTS survey conducted twice in the current EU had yielded filarial antigen positives which were well below the critical cut off values and hence the decision for stoppage of further rounds of MDA was taken and the EU was declared as 'TAS Pass'. However, in view of the active transmission, though below the threshold level care was taken to continue the routine surveillance through existing National Filaria Control Programme (NFCP) units and clinics.

School based TAS conducted in the EU is more feasible than the community-based survey from the point of view of manpower requirement, number of man days required and the cost which are lesser in former type of survey.

Assessment of infection prevalence, whether it be for microfilaremia or for antigenemia, is only a representative survey which may end up in missing the transmission foci that might have emerged due to migration of people from other high burden areas; high vector density in absence of vector control measures. It can be seen in TAS1 results of the current study where $40 \%$ of the positive cases were among migrants.

Inter and intra state migration from other high burden areas which are still under MDA is a common phenomenon in Udupi. The current EU has passed both the TAS however; TAS is not sensitive to detect a change or to identify the hot spots. ${ }^{26}$ In such condition the post MDA surveillance has to be very robust which has to be supported by other complementary tools like Xenomonitoring. Low levels LF infection in vector mosquitoes which are 'non-invasive' to the human population can be detected through xenomonitoring particularly when Culex mosquitoes are involved in transmission. ${ }^{27-29}$ Post MDA surveillance may also be strengthened by strengthening the health care facilities under existing National Filaria Control Programme (NFCP). In addition to these, primary health care facilities may also be involved in periodical assessment of infection prevalence. 
TAS is a scientific, valuable and effective tool to take decision on stoppage of MDA. However, as stated by Chu et al 2013, its utility for longer-term post-MDA surveillance needs further experiential evidence and may be best supported with complementary tools and methods.

\section{Conflict of Interest: None}

\section{References}

1. National Health Policy. Ministry of Health and Family Welfare, Government of India, New Delhi. 2002: 1-39.

2. World Health Assembly. 50.29: Elimination of lymphatic filariasis as a public health problem. Resolutions and Decisions. 1997: 27-8. Available from: who.int/ lymphatic_filariasis/resources/WHA_50\%2029.pdf.

3. World Health Organization. Global programme to eliminate lymphatic filariasis: monitoring and epidemiological assessment of mass drug administration-TAS. 2011. WHO/HTM/NTD/PCT/2011.4.

4. WHO Fact sheet on Lymphatic Filariasis. 2016. Available from: http://www.who.int/mediacentre/factsheets/ fs102/en/.

5. Dreyer G, Coelho G. Lymphatic Filariasis: a potentially eradicable disease. Cadernos de Saúde Pública 1997; 13(3): 537-543. Available from: http://www.scielo. br/scielo.php?script=sci_arttext\&pid=S0102-311X19 97000300030\&Ing=en\&nrm=iso\&tlng=en [PubMed/ Google Scholar].

6. World Health Organization. Lymphatic filariasis: progress of disability prevention activities. Wkly Epidemiol Rec 2004; 79(47): 417-424. Available from: https://www.who.int/lymphatic_filariasis/resources/ who_wer7947/en/ [PubMed/ Google Scholar].

7. World Health Organization. Global programme to eliminate lymphatic filariasis. Progress report 20002009 and Strategic plan 2010-2020. WHO/HTM/NTD/ PCT/2010.6. Available from: https://www.who.int/ lymphatic_filariasis/elimination-programme/en/.

8. Srivastava PK, Dhillon GP. Elimination of lymphatic filariasis in India - a successful endeavor. J Indian Med Assoc 2008; 106(10): 673-674, 676-677. [PubMed/ Google Scholar/ ResearchGate].

9. World Health Organization. Preparing and implementing a national plan to eliminate lymphatic filariasis (in areas where onchocerciasis is not co-endemic). 2000; WHO/ CDS/CPE/CEE/2000.15.

10. World Health Organization. Monitoring and epidemiological assessment of the programme to eliminate lymphatic filariasis at implementation unit level. 2005; WHO/CDS/CPE/CEE/2005.50.

11. Weil GJ, Ramzy RMR. Diagnostic tools for filariasis elimination programs. Trends Parasitol 2006; 23(2): 78-82. [PubMed/ Google Scholar].

12. Helmy H, Weil GJ, Ellethy AS, Ahmed ES, Setouhy ME,
Ramzy RM. Bancroftian filariasis: effect of repeated treatment with diethylcarbamazine and albendazole on microfilaremia, antigenemia and antifilarial antibodies. Trans $R$ Soc Trop Med Hyg 2006; 100(7): 656-662. Available from: https://academic.oup.com/trstmh/ article-abstract/100/7/656/1885493? redirectedFro $\mathrm{m}=$ fulltext [PubMed/ Google Scholar].

13. Swaminathan S, Perumal V, Adinarayanan S, Kaliannagounder K, Rengachari R, Purushothaman J. Epidemiological assessment of eight rounds of mass drug administration for lymphatic filariasis in India: implications for monitoring and evaluation. PLoS Negl Trop Dis 2012; 6(11): e1926. Available from: https:// journals.plos.org/plosntds/article?id=10.1371/journal. pntd.0001926 [PubMed/ Google Scholar].

14. World Health Organization. Global programme to eliminate lymphatic filariasis: monitoring and epidemiological assessment of mass drug administration. A manual for national elimination programmes. Geneva, Switzerland. 2011. Report No.: WHO/HTM/NTD/PCT/2011.4.

15. Unpublished data of independent survey carried out by Medical colleges to study drug compliance after NDA in Udupi district.

16. Cantey PT, Rao G, Rout J. Predictors of compliance with a mass drug administration programme for lymphatic filariasis in Orissa State, India 2008. Trop Med Int Health 2010; 15(2): 224-231. Available from: https:// onlinelibrary.wiley.com/doi/pdf/10.1111/j.13653156.2009.02443.x [PubMed/ Google Scholar].

17. Lahariya C, Mishra A. Strengthening of mass drug administration implementation is required to eliminate lymphatic filariasis from India: an evaluation study. $J$ Vector Borne Dis 2008; 45(4): 313-320. Available from: http://www.mrcindia.org/journal/issues/454313.pdf [PubMed/ Google Scholar].

18. Mukhopadhyay AK, Patnaik SK, Satya Babu P, Rao $\mathrm{KN}$. Knowledge on lymphatic filariasis and mass drug administration (MDA) programme in filaria endemic districts of Andhra Pradesh. J Vector Borne Dis 2008; 45(1): 73-75. Available from: http://www.mrcindia.org/ journal/issues/451073.pdf [PubMed/ Google Scholar].

19. Aswathy S, Beteena K, Leelamoni K. Mass drug administration against filariasis in India: perceptions and practices in a rural community in Kerala. Ann Trop Med Parasitol 2009; 103(7): 617-624. Available from: https://www.tandfonline.com/doi/abs/10.1179/0003 49809X12459740922255 [PubMed/ Google Scholar].

20. Jambulingam P, Swaminathan S, de Vlas SJ, Vinubala C, Stolk WA. Mathematical modelling of lymphatic filariasis elimination programs in India: required duration of mass drug administration and post-treatment level of infection indicators. Parasit Vectors 2016; 9(1): 
501. Available from: https://parasitesandvectors. biomedcentral.com/articles/10.1186/s13071-0161768-y [PubMed/ Google Scholar].

21. Tisch D, Michael E, Kazura JW. Mass chemotherapy options to control lymphatic filariasis: systematic review. Lancet Infect Dis 2005; 5(8): 514-523. Available from: https://www.thelancet.com/journals/laninf/ article/PIIS1473-3099(05)70192-4/fulltext [PubMed/ Google Scholar].

22. Burkot $\mathrm{T}$, Ichimori K. The PacELF programme: will mass drug administration be enough? Trends Parasitol 2002; 18(3): 109-115. Available from: https://europepmc. org/article/med/11854087 [PubMed/Google Scholar].

23. Duerr HP, Dietz K, Eichner M. Determinants of the eradicability of filarial infections: a conceptual approach. Trends Parasitol 2005; 21(2): 88-96. [PubMed/ Google Scholar].

24. Kyelem D, Biswas G, Bockarie MJ, Bradley MH, ElSetouhy $M$, Fischer PU et al. Determinants of success in national programs to eliminate lymphatic filariasis: a perspective identifying essential elements and research needs. Am J Trop Med Hyg 2008; 79(4): 480-484. Available from: http://www.ajtmh. org/docserver/fulltext/14761645/79/4/0790480. pdf?expires $=1579771771 \& i d=i d \&$ accname=guest $\&$ checksum=FC3BBBB174FCD906ADF1EB7F8BB1CA2C [PubMed/ Google Scholar].

25. Boyd A, Won KY, McClintock SK, Donovan CV, Laney SJ, Williams SA et al. A community-based study of factors associated with continuing transmission of lymphatic filariasis in Leogane, Haiti. PLoS Negl Trop Dis 2010; 4(3): e640. Available from: https://journals.plos.org/ plosntds/article?id=10.1371/journal.pntd .0000640 [PubMed/ Google Scholar].

26. Chu BK, Deming M, Biritwum NK, Bougma WR, Dorkenoo AM, El-Setouhy $M$ et al. Transmission assessment surveys (TAS) to define endpoints for lymphatic filariasis mass drug administration: a multicenter evaluation. PLoS Negl Trop Dis 2013; 7(12): e2584. Available from: https://journals.plos.org/plosntds/article?id=10.1371/ journal.pntd.0002584 [PubMed/ Google Scholar].

27. Farid HA, Morsy ZS, Helmy $\mathrm{H}$ et al. A critical appraisal of molecular xenomonitoring as a tool for assessing progress toward elimination of Lymphatic Filariasis. Am J Trop Med Hyg 2007; 77(4): 593-600. http://www.ajtmh. org/docserver/fulltext/14761645/77/4/0770593. pdf?expires $=1579772483 \& i d=i d \&$ accname = guest $\&$ checksum =D 924 AFE 907 BA67FBO 3CD9C2D301CE88C [PubMed/ Google Scholar]

28. Fischer $\mathrm{P}$, Erickson SM, Fischer $\mathrm{K}$ et al. Persistence of Brugia malayi DNA in vector and non-vector mosquitoes: implications for xenomonitoring and transmission monitoring of lymphatic filariasis. Am J Trop Med Hyg
2007; 76(3): 502-507. Available from: http://www.ajtmh. org/docserver/fulltext/14761645/76/3/0760502. pdf?expires $=1579772425 \& i d=i d \&$ accname $=$ guest \& checksum =6E0A5F9894C1C639B 4 EOFFB59628D500 [PubMed/ Google Scholar].

29. Irish SR, Moore SJ, Derua YA, Bruce J, Cameron MM. Evaluation of gravid traps for the collection of Culex quinquefasciatus, a vector of lymphatic filariasis in Tanzania. Trans R Soc Trop Med Hyg 2013; 107(1): 1522. Available from: https://academic.oup.com/trstmh/ article-abstract/107/1/15/1901899?redirectedFrom= fulltext [PubMed/ Google Scholar]. 